\title{
Development and Property Evaluation of FJ-2 Crude Oil Pour Point Depressant
}

\author{
Mengxiang Gao ${ }^{1, a}$, Gang Xie ${ }^{1, b}$, Dengfeng Ju ${ }^{1, c}$, Shuangyan Zhang ${ }^{1, d}$, \\ Hongkui Li ${ }^{2, e}$, Aijun Wei ${ }^{1, f}$, Yanjun Wang ${ }^{2, g}$, Wei Zhang ${ }^{1, h}$, Lili Wei $^{1, i}$, Juan \\ $\mathrm{Xie}^{1, \mathrm{j}}$, Zhi Ma ${ }^{1, k}$, Zhonghai Qin ${ }^{1,1}$
}

${ }^{1}$ Petroleum Production Engineering Research Institute of Huabei Oilfield Company, Renqiu Hebei,062552,P R of China

${ }^{2}$ Huabei Petroleum Tiancheng Industrial Group Co.Ltd, Renqiu Hebei,062552,P R of China accyy_gaomyx@petrochina.com.cn, ${ }^{b}$ cyy_xieg@petrochina.com.cn, ${ }^{c}$ cyy_judf@petrochina.com.cn,

dcyy_zhangsy@petrochina.com.cn, ${ }^{\mathrm{e} T C}$ _LHK@petrochina.com.cn, ${ }^{\mathrm{f}} \mathrm{cyy}$ _weiaj@petrochina.com.cn, 9TC_WYJUN@petrochina.com.cn, ${ }^{\text {'}}$ cyy_zw@petrochina.com.cn,'cyy_weill@petrochina.com.cn, j cyy_xiej@petrochina.com.cn, ${ }^{\mathrm{j}} \mathrm{cyy}$ _maz@petrochina.com.cn, 'cyy_qzh@petrochina.com.cn

Keywords: Pour point depressant,Pour point,Heat-treatment temperature,Fushan crude oil Abstract: The crude oil in Hainan Fushan Oilfield has the characteristics of high pour point(PP) and bad low temperature flow properties. Based on the analysis of Fushan crude oil physical property and test results, the pour point depressant(PPD) FJ-2 was synthesized by the graft copolymerization of vinyl acetate copolymer and modified alkyl amide polymer, which had good susceptibility with the crude oil. The property evaluation results showed that the optimal concentration was $300 \mathrm{mg} / \mathrm{L}$ with the optimal heat treatment temperature $50^{\circ} \mathrm{C}$. The solidification point of the crude oil reduced from $23^{\circ} \mathrm{C}$ to $8^{\circ} \mathrm{C}$. At $20^{\circ} \mathrm{C}$, the apparent viscosity of the crude oil with a concentration of $300 \mathrm{mg} / \mathrm{L}$ was decreased from $918.3 \mathrm{mPa} . \mathrm{s}$ to $165.2 \mathrm{mPa} . \mathrm{s}$, with viscosity reduction rate at $82 \%$; yield value was decreased from $35.17 \mathrm{~Pa}$ to $1.05 \mathrm{~Pa}$, with yield value reduction rate at $97 \%$. In addition, the crude oil treated by FJ-2 had good static stability. The field application showed that the FJ-2 had good adaptability with the crude oil in Hainan Fushan Oilfield, and could lower the pour point, improve the low temperature flow properties of the crude oil.

\section{Introduction}

With the rapid yield increase of high wax content crude oil in recent years, the problem in exploitation and transportation becomes increasingly obvious.It has much more advantage to use chemical ways to reduce the pour point and viscosity of the crude oil . The chemical additive can change the wax crystal form and make it difficult to be the three-dimensional network form at room temperature. It has the effect of reducing the pour point and viscosity, improving the low temperature flow properties of the crude oil,and can supply a new way to solve the problem in oil exploitation and transportation.

The crude oil in Hainan Fushan Oilfield has the characteristics of high wax content and bad low temperature flow properties with the pour point at $23^{\circ} \mathrm{C}$ and wax content at $30 \%$.In recent years, it is colder than the past winter in Haikou,so it brings a new difficulty for the oil transportation in winter. Compared to the heating petroleum pipeline transportation, drug treated pipeline transportation can effectively lower the pour point and apparent viscosity of the crude oil, reduce cost,improve low temperature flow properties and restart property after stopping pipeline transportation $^{[1]}$. Taking into account the air quality of Hainan as an international travel island, saving cost and environment protection, a new type PPD was developed to lower the pour point and improve low temperature flow properties. As PPD commonly has no eurytopicity and has strong selectivity, basing on the physical analysis of Fushan Oilfield crude oil, PPD FJ-2 was synthesized by the graft copolymerization of vinyl acetate copolymer and modified alkyl amide polymer.From the laboratory evaluation and field uses effect,it had good depressive effects,safely supported the 
crude oil cold pipeline transportation of Hainan Fushan Oilfield in winter and energy and cost saving.

\section{Experimental Materials And Instrument}

Experimental Materials. Maleic anhydride, methylbenzene, vinyl acetate, p-Toluene sulfonic acid, crude oil sample(Hua 115-3 Well in Hainan Fushan Oilfield ).

Experimental Instrument .DSY-006A Pour Point Test Instrument, HAAKE MARS Rheometer, FTIR Transform IR Spectrophotometer, FTICR MS.

\section{Experimental Methods And Results}

Crude Oil Analysis.PPD should be developed according to the crude oil property as a result of the complexity of the crude oil formation, the PPD strong selectivity, the different susceptibility for different crude oil ${ }^{[2]}$. The sample of Hua 115-3 Well crude oil was analyzed, the result is shown in Table 1 .

Table 1 Crude oil analysis

\begin{tabular}{ccccc}
\hline $\begin{array}{c}\text { solidification point } \\
{\left[{ }^{\circ} \mathrm{C}\right]}\end{array}$ & $\begin{array}{c}\text { viscosity }\left(40^{\circ} \mathrm{C}\right) \\
{[\mathrm{mPa} \cdot \mathrm{s}]}\end{array}$ & $\begin{array}{c}\text { density }\left(20^{\circ} \mathrm{C}\right) \\
{\left[\mathrm{g} / \mathrm{cm}^{3}\right]}\end{array}$ & $\begin{array}{c}\text { wax } \\
{[\%]}\end{array}$ & $\begin{array}{c}\text { gums \& itumen } \\
{[\%]}\end{array}$ \\
\hline 23 & 4.4 & 0.8622 & 30.00 & 10.89 \\
\hline
\end{tabular}

Wax Structure Test. The wax was separated from the crude oil through the washing of the selective impregnant and the adsorption of the alumina adsorption columniation. The wax structure was measured by FTIR Transform IR Spectrophotometer .The result is shown in Fig.1. Experimental data shows alkyl spectrogram that characteristic such as the absorbed apex contained $-\mathrm{CH}_{2}$ - and $-\mathrm{CH}_{3}$ at $2917 \sim 2849 \mathrm{~cm}^{-1}, \mathrm{C}-\mathrm{H}$ in $\mathrm{CH}_{3}$ flexed and librated at $2962 \mathrm{~cm}^{-1}$. The absorbed apex contained $-\mathrm{CH}_{3}$ at $1473 \sim 1463 \mathrm{~cm}^{-1}, \mathrm{CH}_{2}$ in $-\mathrm{CH}_{3}$ bended and librated at $1411 \mathrm{~cm}^{-1} . \mathrm{CH}_{2}$ swayed and librated at $701 \mathrm{~cm}^{-1}$.

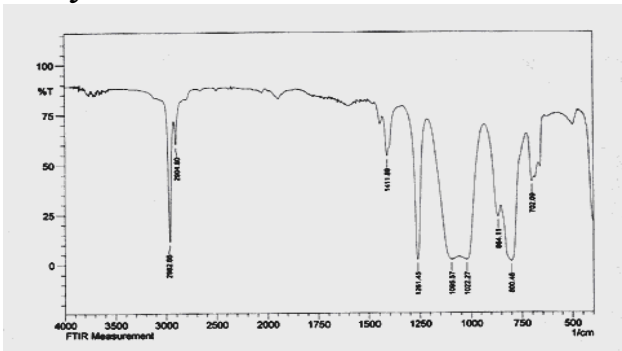

Fig.1 IR spectrum of wax

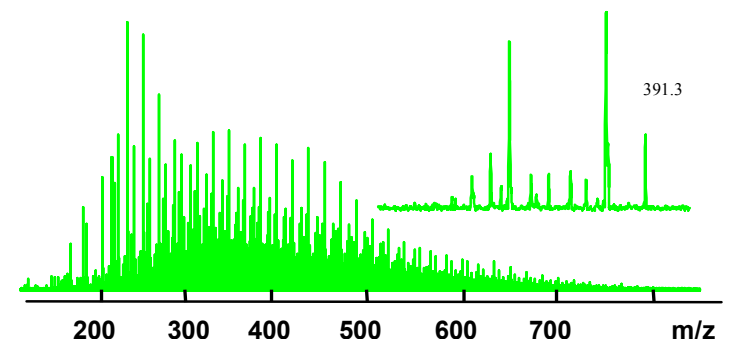

Fig.2 ESI-FT MS spectroscopy of gums

Gums Structure Test. Gums was separated from the crude oil through the washing of the selective impregnant.Using FTICR MS to analyse the molecule structure. The result is shown in Fig.2.Experimental data shows the mass spectrum apices sequent distributed in 220-600 mass range. Local part was outspreaded,many mass spectrum apices could be found in one unit mass range.It shows the gums contains many branch chain structure and has stronger polarity.

FJ-2 PPD Synthesis.(1)Synthesis theory.The experimental results of Hua 115-3 Well crude oil wax and gums test shows wax has unbranched alkyl structure,gums are nitrogenous and oxygenous polarity compound. When designing the PPD molecule structure,polar group should be nitrogenous and oxygenous polarity small molecule compound. Alkyl amides can make wax crystal separate farther as it has stronger polarity and large steric hindrance, the atom have great repulsion. Introducing strong polar group can adjust the PPD polarity,the crystal degree in the solution and increase distributed power to wax crystal.

The reaction equation of vinyl acetate copolymer grafting alkyl maleimide is shown as follows:

(1)Aliphatic amines and maleic anhydride react to be alkyl maleimide. 


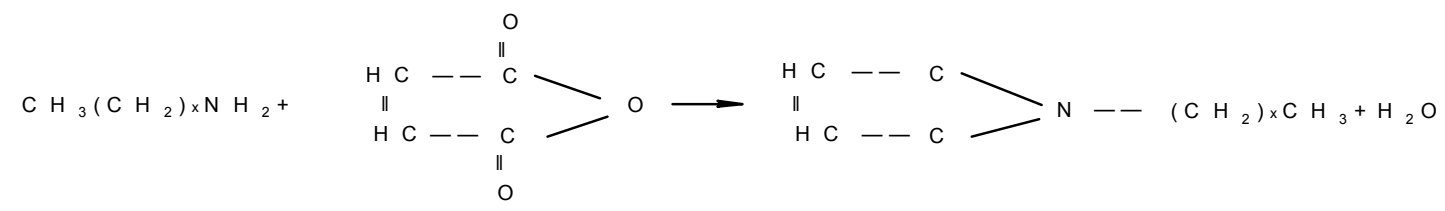

(2) vinyl acetate comes into being big molecule free radical at the effect of initiator.

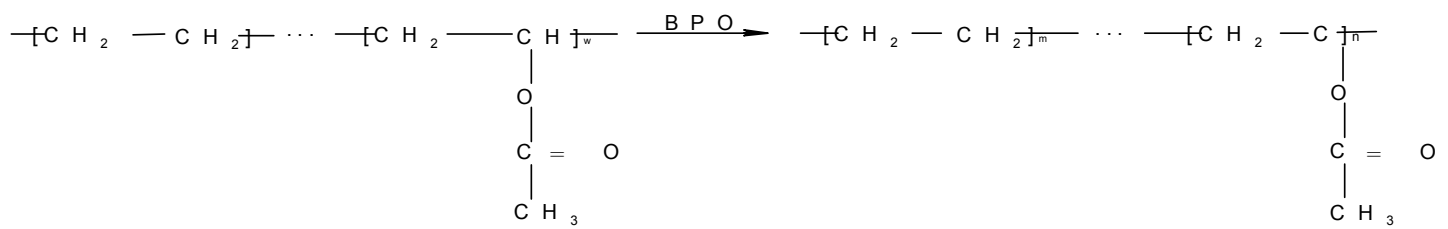

(3) big molecule free radical graft alkyl maleimide.

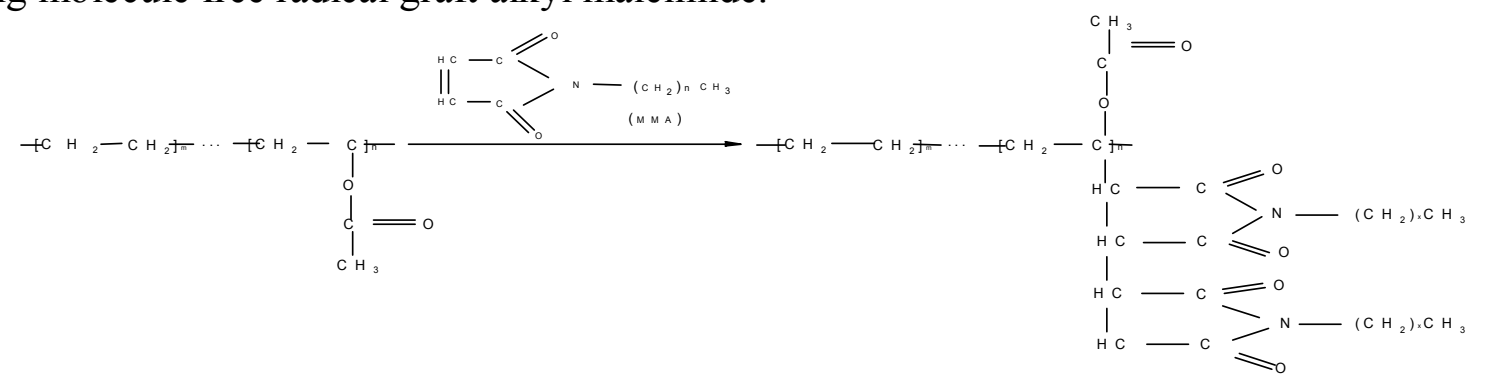

(2)Synthesis methods.Put maleic anhydride dissolved in methylbenzene and p-Toluene sulfonic acid into a reaction bottle, when stirring added aliphatic amines(maleic anhydride: aliphatic amines $=1: 1)$.After reacting for 1 hour at $90^{\circ} \mathrm{C}$, distiled and separated water at $135^{\circ} \mathrm{C}$. When separating water get to the theory value, lowered temperature to $90^{\circ} \mathrm{C}$, then added a certain amount of different molecular weight vinyl acetate copolymer, which was protected by fulling azote gas, finally drop-added initiator to finish the graft opolymerization. (3)Graft copolymers analysis and identification. The reaction product's infrared characteristic absorption peak are shown as the following Fig. 3 5. The infrared characteristic absorption peak of aliphatic amines, maleic anhydride, octadecyl maleimide showed the primary amine functional group of aliphatic amines changed into imide and the graft copolymerization reaction had taken place indeed as the aliphatic amines $\mathrm{N}-\mathrm{H}$ and maleic anhydride $\mathrm{C}=\mathrm{O}$ flexing libration absorption peak all moved to the right.

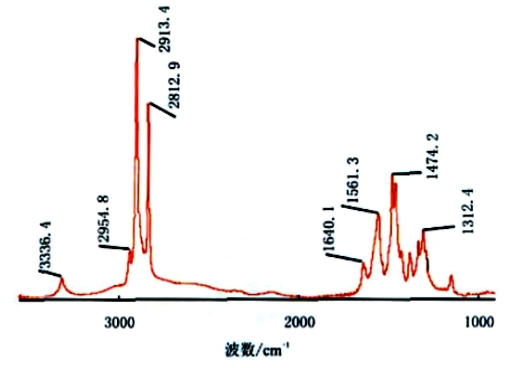

Fig.3 IR spectrum of octadecyl amine

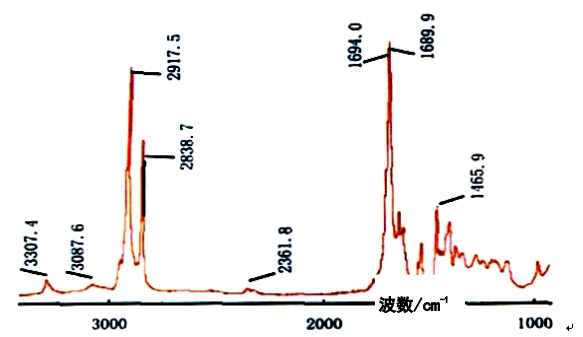

Fig.5 IR spectrum of octadecyl maleimide

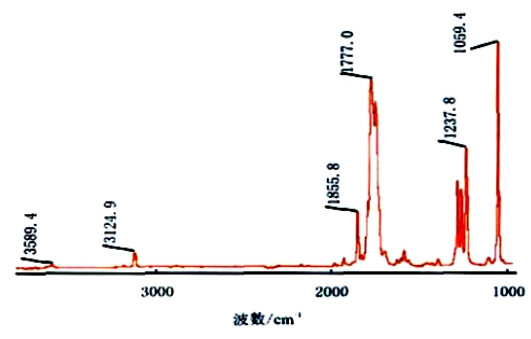

Fig.4 IR spectrum of maleic anhydride

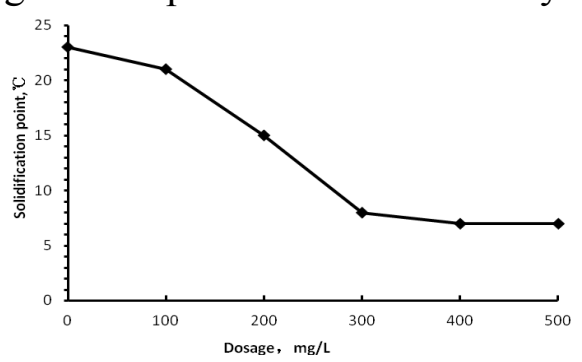

Fig. 6 Influence of PPD dosage on solidification point 
FJ-2 PPD Property Evaluation.(1)Influence of PPD dosage on solidification point.At $55^{\circ} \mathrm{C}$, measured the crude oil solidification point by $100 、 200 、 300 、 400 、 500 \mathrm{mg} / \mathrm{L}$ of FJ-2 PPD.The results are shown in Fig. 6.

The results showed the crude oil solidification point was depressed along with the increase of PPD's adding, and finally the solidification point kept invariable. When $300 \mathrm{mg} / \mathrm{L}$ of PPD was added,the optimal effect of the crude oil solidification point depressing is $8^{\circ} \mathrm{C}$. The depressing tendency was not clear when increasing dosage.So in the field use, $300 \mathrm{mg} / \mathrm{L}$ of PPD was the optimal dosage according to the practical need and production cost.

(2)Influence of treated temperature on solidification point.Based on the adsorption-eutectic pour point depressing theory,the treated temperature must be above the temperature in which the wax all melts ${ }^{[3]}$.In the drug-treated pipeline transportation,the effect of pour point depressing won't be better if the treated temperature is lower even if increase the PPD dosage.Put the crude oil sample at $300 \mathrm{mg} / \mathrm{L}$ of PPD in the constant temperature water bath at $40 \sim 60^{\circ} \mathrm{C}$ for heating. Tested the solidification point of the drug-treated sample to see the effects of different treated temperature on crude oil solidification point. The results are shown in Table 2.

Table 2 Influence of treated temperature on solidification point

\begin{tabular}{cccccc}
\hline Treated temperature,$\left[{ }^{\circ} \mathrm{C}\right]$ & 40 & 45 & 50 & 55 & 60 \\
Solidification point, $\left[{ }^{\circ} \mathrm{C}\right]$ & 23 & 22 & 8 & 8 & 7
\end{tabular}

The results showed PPD had the optimal effect of the pour point depressing when the treated temperature is above $50^{\circ} \mathrm{C}$. The effect won't be good when the treated temperature is below $50^{\circ} \mathrm{C}$ because the wax,gums, bitumen in the crude oil and the added PPD are not active, it is hrad to form the wax crystal structure to improve the crude oil low temperature flowing property.So the PPD optimal treated temperature is $50^{\circ} \mathrm{C}$.

(3)Influence on the crude oil viscosity and yield value.At $300 \mathrm{mg} / \mathrm{L}$ and $50^{\circ} \mathrm{C}$, tested the PPD's effects on the crude oil viscosity and yield value.The results are shown in Table 3.

Table 3 Influence on the crude oil viscosity and yield value

\begin{tabular}{cccc}
\hline $\begin{array}{c}\text { Untreated crude } \\
\text { viscosity }\left(20^{\circ} \mathrm{C}\right) \\
{[\mathrm{mPa} . \mathrm{s}]}\end{array}$ & $\begin{array}{c}\text { Treated crude } \\
\text { viscosity }\left(20^{\circ} \mathrm{C}\right) \\
{[\mathrm{mPa} . \mathrm{s}]}\end{array}$ & $\begin{array}{c}\text { Untreated crude } \\
\text { yield value } \\
\left(20^{\circ} \mathrm{C}\right)[\mathrm{Pa}]\end{array}$ & $\begin{array}{c}\text { Treated crude } \\
\text { yield value } \\
\left(20^{\circ} \mathrm{C}\right)[\mathrm{Pa}]\end{array}$ \\
\hline 918.3 & 165.2 & 35.17 & 1.05 \\
\hline
\end{tabular}

The results show that after adding PPD the low temperature flow property of the crude oil was improved and the viscosity and yield value reduced largely. At $20^{\circ} \mathrm{C}$, the ratio of viscosity reduction was $82 \%$ by shear rate $22 \mathrm{~s}^{-1}$, the ratio of yield value reduction was $97 \%$ by shear rate $0.2 \mathrm{~s}^{-1}$.

(4)Static stability test.Static state stability experiment can test the solidification point changing situation of the drug-treated crude oil in static state when the pipeline transportation shut. Experienced different temperature and high speed shear along the pipeline, the crude oil flow property will also change along with the time after stopping transportation ${ }^{[4]}$.

Heated the crude oil with $300 \mathrm{mg} / \mathrm{L}$ of PPD to $50^{\circ} \mathrm{C}$, then naturally cooled to $20^{\circ} \mathrm{C}$, tested the viscosity and solidification point during the 7 days' static state. The results are shown in Table 4.

Table 4 Static stability test

\begin{tabular}{cccccccc}
\hline \multirow{2}{*}{ Article } & \multicolumn{7}{c}{ Time[day] } \\
\cline { 2 - 8 } & 1 & 2 & 3 & 4 & 5 & 6 & 7 \\
\hline Viscosity $\left(20^{\circ} \mathrm{C}\right)[\mathrm{mPa} . \mathrm{s}]$ & 175 & 175 & 175 & 175 & 175 & 175 & 175 \\
\hline Solidification point $\left[{ }^{\circ} \mathrm{C}\right]$ & 10 & 10 & 10 & 10 & 10 & 10 & 10 \\
\hline
\end{tabular}

The results show PPD could reduce the viscosity and solidification point.After 7 days' static state, the viscosity and solidification point of the drug-treated crude oil didn't change .It shows PPD had good static state stability. 


\section{Field Application}

In November 2013,FJ-2 PPD was used in the field according to its' use characteristic and Hainan Fushan Oilfield situation by the way of wellbore injection. The crude oil was sampled the next day after field use.In the 7 days' test, the crude oil solidification point was $10^{\circ} \mathrm{C}$ to $12^{\circ} \mathrm{C}$, which was reduced by $12^{\circ} \mathrm{C}$ compared with the solidification point drug-treated before. The low temperature flow properties of the crude oil were improved obviously.

\section{Conclusions}

(1) By the effect of the free radical, FJ-2 PPD suiting for Fushan Oilfield crude oil is successfully synthesized by the graft copolymerization of aliphatic amines, maleic anhydride and vinyl acetate copolymer. The use of PPD can be more economic and reasonable by correctly using dosage and heat-treated temperature.

(2) The optimum addition of this PPD is $300 \mathrm{mg} / \mathrm{L}$, and the optimum treatment temperature is $50^{\circ} \mathrm{C}$. The experimental result shows the crude oil solidification point is reduced by $15{ }^{\circ} \mathrm{C}$.At 20 ${ }^{\circ} \mathrm{C}$, the ratio of crude oil apparent viscosity reduction is $82 \%$, the ratio of yield value reduction is $97 \%$.From the results of 7 days'test,PPD has good stability.

(3) In field use, the crude oil solidification point is reduced by $12{ }^{\circ} \mathrm{C}$ and the low temperature flow properties of the crude oil is improved effectively.

\section{References}

[1] Xingqqiong Duan, Jiaqiang Jing, Linglin Lei etc.Oil and Gas Transportation and Storage,Vol 30,No 3,Jun 2012.Pg12-14.In Chinese.

[2] Huajian Wang, Suxin Xu, Yuan Lin etc.Fault-Block Oil \& Gas Field, Vol 16,No 6, Nov 2009.Pg126-128.In Chinese.

[3] Yinqing Liu, Wanli Kang, Yimei Ma etc.Journal of Daqing Petroleum Institute, Vol 30, No 3,Jun 2006.Pg40-42.In Chinese.

[4] Chen Rong, Yuhe Zhou.Advances In Fine Petrochemicals, Vol 12,No 2,Feb 2011.Pg14-16.In Chinese. 